\title{
La institucionalización del aprendizaje-servicio solidario en la Orquesta-Escuela de Chascomús
}

\author{
Geronimo Daguerre \\ Universidad Nacional de La Plata, Argentina
}

\section{Resumen}

El aprendizaje-servicio solidario es una propuesta de innovación educativa para los procesos de enseñanza-aprendizaje, con amplia difusión en el panorama internacional. Sin embargo todavía no abundan desarrollos que se enfoquen en el campo musical y en especial en sistemas educativos no formales. A partir de la revisión de documentos institucionales, la observación de diferentes proyectos y entrevistas grupales a diversos actores, se intenta establecer una línea de base tanto para favorecer la institucionalización de estas prácticas, como para implementar un futuro modelo evaluativo sobre el impacto socioeducativo que tiene este proyecto para la comunidad, sus alumnos y la escuela.

\section{Palabras clave}

Rúbrica, desarrollo organizacional, aprendizaje-servicio solidario, orquesta escuela. 


\title{
The institutionalization of Solidarity Service Learning in the practices of the Orchestra School of Chascomús
}

\begin{abstract}
Solidarity Service Learning is an educational innovation proposal that optimizes teaching-learning processes, which has acquired great academic relevance and wide dissemination in the international scene. However, these practices are not yet common in the area of developments that focus on the musical field and especially on non-formal educational processes. Based on a review of the institutional documents of the Orchestra School of Chascomús, a visit to its different projects and interviews with various agents involved in the establishment and development of this school, this paper attempts to establish a baseline in order to both promote the institutionalization of their practices and to implement a model for the future evaluation of the socioeducational impact that this project has for the community, its students and the school.
\end{abstract}

\section{Keywords}

Rubric, organizational development, solidarity service learning, school orchestra. 


\section{Introducción}

La Orquesta-Escuela de Chascomús (OECh) promueve iniciativas conjuntas en diferentes localidades de la Argentina con la finalidad de potenciar las acciones territoriales destinadas a revertir situaciones de desigualdad educativa, social y cultural.

De esta manera los alumnos aprenden y se desarrollan a través de la participación en programas $\mathrm{y} / \mathrm{o}$ proyectos, que se realizan en la comunidad y se dirigen a satisfacer las necesidades de la misma. Algunas actividades surgen como propuestas de articulación con instituciones educativas y comunitarias locales, en las que se ofrecen espacios didácticos-musicales de acuerdo al perfil que se aspira impactar. Dichas actividades se coordinan con escuelas primarias, secundarias u organizaciones barriales, y programas de servicio comunitario; esto promueve ciudadanía al mismo tiempo que invita a formar parte de las actividades dentro de la Orquesta

\section{Experiencia desarrollada}

La rúbrica de Furco (2005) sirvió para establecer una serie de criterios sobre los cuales fuera posible medir la institucionalización del aprendizajeservicio en la Orquesta-Escuela de Chascomús, en el año 2019.

Los objetivos planteados fueron los siguientes:

- Operacionalizar la rúbrica de Furco al desarrollo organizacional de la Orquesta-Escuela;

- Problematizar el grado de institucionalización de las prácticas de aprendizaje-servicio;

- Establecer un panorama previo para realizar una evaluación de impacto del proyecto en la comunidad a través del método de control sintético.

Dicha rubrica facilitó los grupos focales de discusión entre actores y permitió medir ciertos logros alcanzados para determinar el estatus de la institucionalización y asegurar la futura realización de un esfuerzo sistemático y comprensible en el impulso de estas prácticas hacia la comunidad. A continuación se explica la concreción de cada una de las dimensiones.

\subsection{Dimensión 1. Misión del aprendizaje-servicio solidario}

El desarrollo de una definición a nivel de toda la organización sobre el aprendizaje-servicio permite entregar significado, focalización, y énfasis a los esfuerzos de la misma. Lo anterior involucra a los actores de la institución que participan y define el grado en el que el aprendizaje-servicio es parte constitutiva de la organización. La Orquesta-Escuela de Chascomús se encuentra en una etapa de construcción, ya que todavía hay ciertas inconsistencias en la aplicación de una definición concreta.

Se entiende que la definición de este concepto es una dimensión fundamental y previa para el logro de su institucionalización. Si bien se han

Daguerre, G. (2020). La institucionalización del aprendizaje-servicio solidario en la Orquesta-Escuela de Chascomús. RIDAS, Revista Iberoamericana de Aprendizaje Servicio, 9, 155-161. 
definido algunas metas de corto y largo plazo, no han sido formalizadas dentro de un planeamiento estratégico que guíe la implementación de dichas metas. La organización aún no cuenta con un planeamiento estratégico, lo que de alguna manera imposibilita también que el aprendizaje-servicio sea parte constitutiva de la misma.

Por otra parte, si bien ciertos rasgos y características del aprendizaje-servicio han sido comúnmente mencionados como parte importante de la misión institucional, todavía esto no se encuentra incluido en la misión oficial.

Finalmente el nivel más débil de esta dimensión es el que refiere a la alineación con las reformas educativas, ya que si bien se desarrollan esfuerzos para generar alianzas entre la Orquesta, la escuela y la comunidad, la particularidad de esta organización reside en que interactúa con diversos actores del sistema educativo formal estando al mismo tiempo fuera del mismo.

En definitiva si bien la definición del aprendizaje-servicio tiene un significado implícito para algunos actores dentro de la organización, existen quienes ponen énfasis para extender esto al nivel de toda la organización. Por el momento no es posible focalizar estos esfuerzos en una dirección concreta que permita hacer del aprendizaje-servicio parte constitutiva de la Orquesta-Escuela de Chascomús.

\subsection{Dimensión 2. Apoyo e} involucramiento de los docentes en el aprendizaje-servicio solidario
Se observa que un número de miembros conocen que es aprendizajeservicio o comprenden de modo implícito en qué medida el aprendizajeservicio es diferente al servicio comunitario, voluntariado u otras actividades de aprendizaje experiencial.

La Orquesta-Escuela de Chascomús se encuentra en una etapa de creación, debido a que muy pocos docentes son defensores del aprendizaje-servicio en su trabajo dentro de la organización. Estas actividades son respaldadas por un reducido número de docentes. Existe una polarización entre el perfil técnicomusical frente a otro mayormente ligado a la defensa de la educación integral mediante el compromiso social. Estos perfiles coexisten de manera notable en el equipo, sin embargo en cuanto al liderazgo, el perfil vinculado con la educación integral se configura hacia el interior de la organización como un grupo de docentes respetado e influyentes que sirven como líderes o defensores de las prácticas del aprendizaje-servicio. Este componente podría servir como una iniciativa futura fundamental en el camino hacia la institucionalización sustentable del aprendizaje-servicio.

Finalmente el aspecto más débil de esta dimensión es el incentivo y reconocimiento a los docentes, ya que si bien existen motivos personales para que estos se involucren en actividades relacionadas con el aprendizajeservicio, igualmente expresan cierta falta de reconocimiento en la evaluación de su participación en estos procesos.

2.3 Dimensión 3. Apoyo e involucramiento de los alumnos en el

Daguerre, G. (2020). La institucionalización del aprendizaje-servicio solidario en la Orquesta-Escuela de Chascomús. RIDAS, Revista Iberoamericana de Aprendizaje Servicio, 9, 155-161. 
aprendizaje-servicio solidario

Un elemento importante para la institucionalización del aprendizajeservicio es el grado en que los alumnos son conscientes de las oportunidades que poseen para desempeñar roles de liderazgo en el desarrollo del aprendizaje-servicio. Si bien existen algunos mecanismos para informar a los alumnos acerca de las actividades relacionadas con el aprendizajeservicio, muchas veces estos desconocen los recursos y oportunidades que la institución brinda, dado que estas se concentran en algunos programas o actividades.

Si bien este aspecto se ubica en una etapa de construcción, debido a la falta de ciertos recursos y mecanismos de información institucionales, por otro lado se observa que las oportunidades para los alumnos gozan de una institucionalización sustentable, dado que las opciones y oportunidades en donde el aprendizaje-servicio se integra a la esencia de las actividades, se presentan disponibles para los alumnos sin consideraciones de edad, años en la organización e intereses.

En cuanto al liderazgo de los alumnos, se ve reflejado en su participación y desempeño al interior de cada formación orquestal, existiendo todavía un limitado número de oportunidades para que estos tomen roles de liderazgo en el fomento del aprendizaje-servicio hacia la organización en su conjunto. Lo anterior surge como un aspecto que institucionalmente está relacionado mayormente con el rol docente.

Finalmente, el incentivo y reconocimiento a los alumnos, al igual que lo ocurrido con los docentes, se presenta también como un aspecto a mejorar o en construcción, ya que si bien la organización ofrece algunos incentivos y reconocimiento informales, igualmente estos todavía resultan insuficientes en comparación a las oportunidades que la organización ofrece a sus alumnos.

\subsection{Dimensión 4. Participación y asociación con socios comunitarios}

Un elemento importante para la institucionalización del aprendizajeservicio es el grado en que la organización fomenta relaciones colaborativas con los socios comunitarios (organizaciones comunitarias, públicas o privadas), y la medida en que fomenta a los representantes de estas organizaciones a desempeñar roles en la implementación e impulso del aprendizaje-servicio.

La Orquesta-Escuela de Chascomús se encuentra en una etapa de construcción, debido a que solo algunos de los socios comunitarios, pero no la mayoría, están conscientes de las metas que la organización tiene con respecto al aprendizaje-servicio y el rango completo de oportunidades de aprendizaje-servicio que los alumnos poseen.

En cuanto al entendimiento mutuo que existe entre la Orquesta-Escuela de Chascomús y sus socios comunitarios, solo algunos son conscientes de las necesidades del otro, los tiempos, objetivos, recursos y las capacidades que cada uno se ha planteado o posee

Daguerre, G. (2020). La institucionalización del aprendizaje-servicio solidario en la Orquesta-Escuela de Chascomús. RIDAS, Revista Iberoamericana de Aprendizaje Servicio, 9, 155-161. 
para desarrollar e implementar actividades de aprendizaje-servicio. Debido a esto es que en ocasiones se manifiestan discrepancias entre los objetivos de cada socio.

En este sentido existen pocas oportunidades para que las personas representantes de los socios comunitarios lideren el fomento del aprendizaje-servicio, ya que estos no son comúnmente incentivados a expresar las necesidades específicas de sus organizaciones, sino que más bien se adecuan a los tiempos, objetivos, recursos y capacidades de la OECh. Esto permite observar para la Orquesta un alto grado de asociación con la comunidad, en referencia a las diferentes actividades de aprendizajeservicio, pero al mismo tiempo un bajo nivel de participación de sus socios comunitarios en roles de implementación e impulso de las actividades.

2.5 Dimensión 5. Apoyo institucional al aprendizaje-servicio solidario

El equipo directivo de la OrquestaEscuela de Chascomús se constituye como la entidad coordinadora que abarca toda la organización, y no solo se dedica a coordinar exclusivamente actividades de aprendizaje-servicio, esto genera que los servicios solo se provean a algunos actores o a parte reducida de la organización. En este sentido si bien la coordinación toma decisiones que reconocen el aprendizaje-servicio como un objetivo educacional esencial para la organización, todavía no se han desarrollado políticas oficiales direccionadas en este sentido. Además si bien el equipo administrativo de la organización posee un claro entendimiento acerca del aprendizajeservicio, todavía no ha realizado el esfuerzo suficiente para que el aprendizaje-servicio se visibilice y vuelva a una parte importante de la organización.

Existe un número apropiado de personas en el equipo de trabajo que comprenden completamente el aprendizaje-servicio y que poseen cargos apropiados desde los cuales pueden influenciar el impulso y la institucionalización dentro de la Orquesta. Sin embargo su involucramiento es temporal o está financiado a través de fondos de corto plazo o externos a la organización. Esto genera ciertas inconsistencias en cuanto al esfuerzo y la participación de sus miembros, haciendo que la cultura organizacional dificulte la continuidad del proceso de institucionalización del aprendizaje-servicio. Por otro lado existen todavía muy pocas orquestas en el país que reconozcan al aprendizajeservicio como una parte de sus programas musicales.

Finalmente en cuanto al aspecto de evaluación que se plantea en la quinta dimensión, se considera que gran parte de este trabajo representa un esfuerzo sistemático y vigente para desarrollar una propuesta de seguimiento acerca del número y la calidad de las actividades de aprendizaje-servicio que desarrolla la Orquesta-Escuela de Chascomús actualmente.

\section{Reflexiones finales}

Algunas experiencias demostraron que

Daguerre, G. (2020). La institucionalización del aprendizaje-servicio solidario en la Orquesta-Escuela de Chascomús. RIDAS, Revista Iberoamericana de Aprendizaje Servicio, 9, 155-161. 
muchas veces no se tuvieron en cuenta las alianzas territoriales, ni la colaboración de ciertas instituciones, haciendo que la vinculación con el aprendizaje-servicio fuera bilateral. Con alguna escuela la responsabilidad era desproporcionada, ya que la desvinculación con el resto de las organizaciones comunitarias, generó un sentido negativo en cuanto a la pertenencia de este proyecto.

Si las actividades en una escuela finalizaban se terminaba el proyecto de servicio comunitario y frente a esto, en ocasiones la escuela no terminaba de constituirse en un agente activo que propicie las tareas de promoción humana. En otros casos, no hubo entre el aprendizaje-servicio y la tarea áulica; ya que el planteo pareciera ser totalmente extracurricular, con lo que se afectaba la inserción del aprendizaje-servicio en la escuela.

En los proyectos que tuvieron como objetivo fortalecer los compromisos del alumnado con la escuela, el aprendizaje-servicio entraba en juego sólo en forma tangencial, ya que los esfuerzos se dirigieron a apuntalar el compromiso escolar y el sentido de pertenencia de los alumnos con la escuela. En estos casos, la relación horizontal de la Orquesta-Escuela de Chascomús con la escuela y la comunidad se vio comprometida, ya que la escuela tiende a asumir una posición central, intentando absorber al espacio comunitario.

En general se vio que los organismos de la comunidad local trabajan aspectos educativos a través del apoyo escolar, trabajando en el marco de la contención y fomentando la reinserción de niños y jóvenes en el sistema educativo desde el aprendizaje-servicio desarrollado en la Orquesta-Escuela de Chascomús.

\section{Referencias bibliográficas}

Furco, A. (2005). Impacto de los proyectos de aprendizaje servicio. Aprendizaje y servicio solidario en la Educación Superior y en los sistemas educativos latinoamericanos. Actas del 70 Seminario Internacional Aprendizaje y Servicio Solidario, Buenos Aires (Argentina), 19-26. Recuperado de http://www.ucv.ve/fileadmin/user_uplo ad/facultad_ciencias_juridicas/cservicio cominitario/AprendizajeyservicioenlaEd ucaciOnSuperior_y_en_sistemaseducati voslatinoamericanos.pdf

Daguerre, G. (2020). La institucionalización del aprendizaje-servicio solidario en la Orquesta-Escuela de Chascomús. RIDAS, Revista Iberoamericana de Aprendizaje Servicio, 9, 155-161. 